\title{
Multi-Stage Intelligent Smart Lockdown using SIR Model to Control COVID 19
}

\author{
Abdul Ghaffar ${ }^{1}$, Saad Alanazi ${ }^{2}$, Madallah Alruwaili ${ }^{2}$, Mian Usman Sattar ${ }^{3}$, Waqas Ali $^{4}$, \\ Memoona Humayun ${ }^{2}$, Shahan Yamin Siddiqui ${ }^{5,6}$, Fahad Ahmad ${ }^{7}$ and Muhammad Adnan Khan ${ }^{8, *}$
}

\author{
${ }^{1}$ Department of Information System, University of Management and Technology, Lahore, Pakistan \\ ${ }^{2}$ College of Computer and Information Sciences, Jouf University, Sakaka, 72341, Saudi Arabia \\ ${ }^{3}$ School of Business, Beaconhouse National University, Lahore, Pakistan \\ ${ }^{4}$ Department of Computer Science, University of Management and Technology, Lahore, Pakistan \\ ${ }^{5}$ School of Computer Science, Minhaj University Lahore, Lahore, 54000, Pakistan \\ ${ }^{6}$ School of Computer Science, National College of Business Administration and Economics, Lahore, 54000, Pakistan \\ ${ }^{7}$ Department of Basic Sciences, Deanship of Common First Year, Jouf University, Sakaka, 72341, Saudi Arabia \\ ${ }^{8}$ Riphah School of Computing \& Innovation, Faculty of Computing, Riphah International University, Lahore Campus, Lahore, \\ 54000, Pakistan \\ *Corresponding Author: Muhammad Adnan Khan. Email: adnan.khan@riphah.edu.pk \\ Received: 08 October 2020; Accepted: 24 February 2021
}

\begin{abstract}
Corona Virus (COVID-19) is a contagious disease. Unless an effective vaccine is available, various techniques such as lockdown, social distancing, or business Standard operating procedures (SOPs) must be implemented. Lockdown is an effective technique for controlling the spread of the virus, but it severely affects the economy of developing countries. No single technique for controlling a pandemic situation has ever returned a promising result; therefore, using a combination of techniques would be best for controlling COVID-19. The South asian association of regional corporation (SAARC), region contains populous and developing countries that have a unique social-cultural lifestyle that entails a higher rate of contact and $R_{0}$. The per-capita income and economic conditions of these countries are dismal in comparison with those of advanced countries. With no lockdown policy, their healthcare systems would be unable to provide support. In this study, an intelligent smart lockdown strategy is proposed, which is dynamically implemented with the Susceptible, infectious, or recovered (SIR) model by calculating the $R_{0}$ value after a certain number of days to implement multi-stage lockdowns with social distancing and SOPs for conducting business. Only $4.28 \%$ of the population of SAARC countries would be affected by COVID-19 after July 22, 2021 under the proposed strategy. Nearly $38 \%$ of the population would be affected after March 8, 2021 without lockdowns, whereas $18 \%$ of the population would be affected according to the simple SIR model after May 30, 2021. Furthermore, less than $1 \%$ of the population would be affected after April 13, 2021 under full lockdown and recession. Thus, the proposed strategy shows promising long-term results for controlling COVID-19 without negatively affecting the economy.
\end{abstract}

Keywords: Covid-19; saarc; south asia; smart lockdown; intelligent smart lockdown

This work is licensed under a Creative Commons Attribution 4.0 International License, which permits unrestricted use, distribution, and reproduction in any medium, provided the original work is properly cited. 


\section{Introduction}

Severe respiratory syndrome (SARS) is a respiratory illness caused not long ago by various coronavirus types. The novel coronavirus (2019-nCoV), which is a newly discovered virus of the SARS-CoV family, is responsible for a new epidemic that began in Wuhan City, China on December 12, 2019 [1]. This new disease COVID-19 is linked with cases of pneumonia reported in a local seafood wholesale market [2]. The most frequent symptoms of COVID-19 patients included dry cough, headache, high fever, breathing difficulties, and pneumonia in the most severe cases. Due to the extended incubation period of this coronavirus, which ranges from 7 to 14 days [3], there may be no apparent symptoms initially. After the incubation period, the patient shows the symptoms mentioned, but has already transmitted the virus to the non-infectious population. One danger of COVID-19 is that it slowly makes the respiratory system nonfunctional and leads patients toward immediate death. The CDC has reported that this virus is now a worldwide respiratory disease that can be transmitted from person to person. Due to the unavailability of effective vaccines, there is no way to control it directly, so the World health organization (WHO) and CDC have recommended various indirect techniques, including social distancing, cleanliness especially handwashing habits, patient isolation, and self-quarantine.

The South asian regional corporation association (SAARC) is a regional development organization for South Asian countries, including Pakistan, India, Bangladesh, Sri Lanka, Nepal, the Maldives, Bhutan, and Afghanistan. Pakistan, India, Nepal, and Bhutan have an important border with China, where coronavirus outbreaks were first reported. Pakistan and Afghanistan have a common border with Iran, another main source of COVID-19 outside of China. The SAARC countries have a limited healthcare system. India reserves only $1.28 \%$ of its Gross domestic product (GDP) for its healthcare system [4], thus they cannot cope with the exponential growth of COVID-19 patients. Another aspect of the SAARC countries is the low average monthly income, which leads to the ineffectiveness of lockdowns in controlling COVID-19. As overall border security is quite obscure, several illegal border crossings have already been reported, so the increase in virus spread in any country will lead to equivalent risk in other SAARC countries. As only 3.46 tests out of 100 in India and 3.10 tests out of 100 in Pakistan were carried out on June 8, 2020, the COVID-19 situation was adequately managed in the SAARC countries, while 7.143 tests out of 100 were carried out in Italy [5], so the spread of the virus was much higher there.

The proposed strategy was implemented dynamically with the SIR model to predict the size of the epidemic in the SAARC countries. Several researchers have already implemented the simple SIR model and its modified forms to predict the spread of past epidemics, as well as the novel COVID-19 pandemic, but they could not forecast the outcome without knowing the impact of social distancing, lockdown, and quarantine, which reduce the extent of virus spread. Thus, the expected outcomes of these models are not practical to predict. The proposed multi-stage intelligent smart lockdown is implemented using a dynamic SIR model with the impact of social distancing and lockdowns. It automatically switches between lockdown stages to overcome the effects of the epidemic and maintain the country's economic stability. So, the proposed strategy is a better solution for making a more accurate prediction of COVID-19 spread and delaying the period of peak infection to prepare people to cope with the pandemic situation effectively and carry out business activities to maintain the economy [6-8].

The COVID-19 situation is one that has not occurred before. Some countries have adopted a 100 percent lockdown and have faced poor economic results. We propose an intelligent smart lockdown strategy that, if adopted in this situation, will have less severe effects on the economies of the SAARC countries, which are already below the world average due to economic factors natural resources, infrastructure, gross domestic product, technology, and law.

The rest of this research work is organized as follows: Section II gives a brief review of the research related to this area. Section III gives the details of the data collection and methodology used to conduct 
this research. Section IV discusses the experimental setup and results. Lastly, the article is concluded with a discussion in Section V.

\section{Related Work}

An infectious disease is the main reason for any pandemic situation, and the risk of its propagation becomes greater and more dangerous for human health due to the social networks of people and animals. Infectious diseases can be controlled by restricting interactions between individuals [9]. The use of quarantine, health awareness, and large-scale screening can also effectively control such epidemics [10]. Social distancing and isolation slow down the spread of COVID-19, minimize its intensity, and support the healthcare system by preventing a bottleneck [11]. Intensive testing and screening, the use of quarantine and isolation, and limiting contact were effectively applied to minimize the effect of COVID-19 in Bhutan, whereas Pakistan and India did not perform intensive testing [12]. The Spanish flu killed millions of people in 1918 because they did not follow any proper lockdown or social distancing policies [7]. In contrast, an epidemic of the African cassava mosaic disease in 1988 was adequately controlled by following appropriate social distancing techniques and a complete lockdown [6]. The size of the novel COVID-19 pandemic was also estimated by using a simple SIR model in [6-8]. Researchers from the SAARC countries have also tried to study machine learning to conclude how we can minimize the cost of the selection process in the diagnostic model for COVID-19 [8]. To control such a disease that has no vaccine is not easy, so some researchers have proposed artificial intelligence-oriented methodologies to obtain useful information from the large-scale dataset of the infected and susceptible populations [8].

\subsection{COVID-19 in SAARC Countries}

The first case in SAARC countries was reported on 24 January 2020 in Nepal in a traveler who had returned from China [13]. In the SAARC countries, the number of cases continuously increased rapidly after that. The SAARC region is a new hot spot of coronavirus due to a higher value of $R_{0}$, the reproduction number, of 2.13, which is more than the 1.92 of Italy but less than the 2.22 of the USA. As there has been a declining trend in the $R_{0}$ value in the SAARC countries due to lockdown, it has remained between 2.0 and 2.5 over the last two months, as shown in Fig. 1. The high value of $R_{0}$ and poorly managed conditions of COVID-19 foretell the spread of the virus and high death tolls in the SAARC region for the expected second wave in the coming days. However, the SAARC countries are in a better position in terms of mortality rate $(\vartheta)$, which indicates mild effects of COVID-19 due to the large size of the young generation and their excellent immune systems. However, due to the low level of resources and weak healthcare systems, the risk of virus spread may be significant in the SAARC countries.

\subsection{Controlling the Pandemic Situation}

Any pandemic situation can be controlled by social distancing and lockdowns. The use of both techniques improves the transmission rate $(\gamma)$, ultimately overcoming the spread of an epidemic. If there is no such technique to restrict transmission, then it grows exponentially. If one infectious person can infect $\mathrm{x}$ other persons each day and render them infectious, then the infectious population (I) grows according to Eq. 1. If one infected person can infect only one person, then all the SAARC region population will be infected within 42 days according to Eq. (1), where $\mathrm{x}=1$. Various techniques, such as social distancing and lockdown, are needed in controlling exponential growth, and indirectly impact epidemic growth.

$I=(1+x)^{n-1}$ 


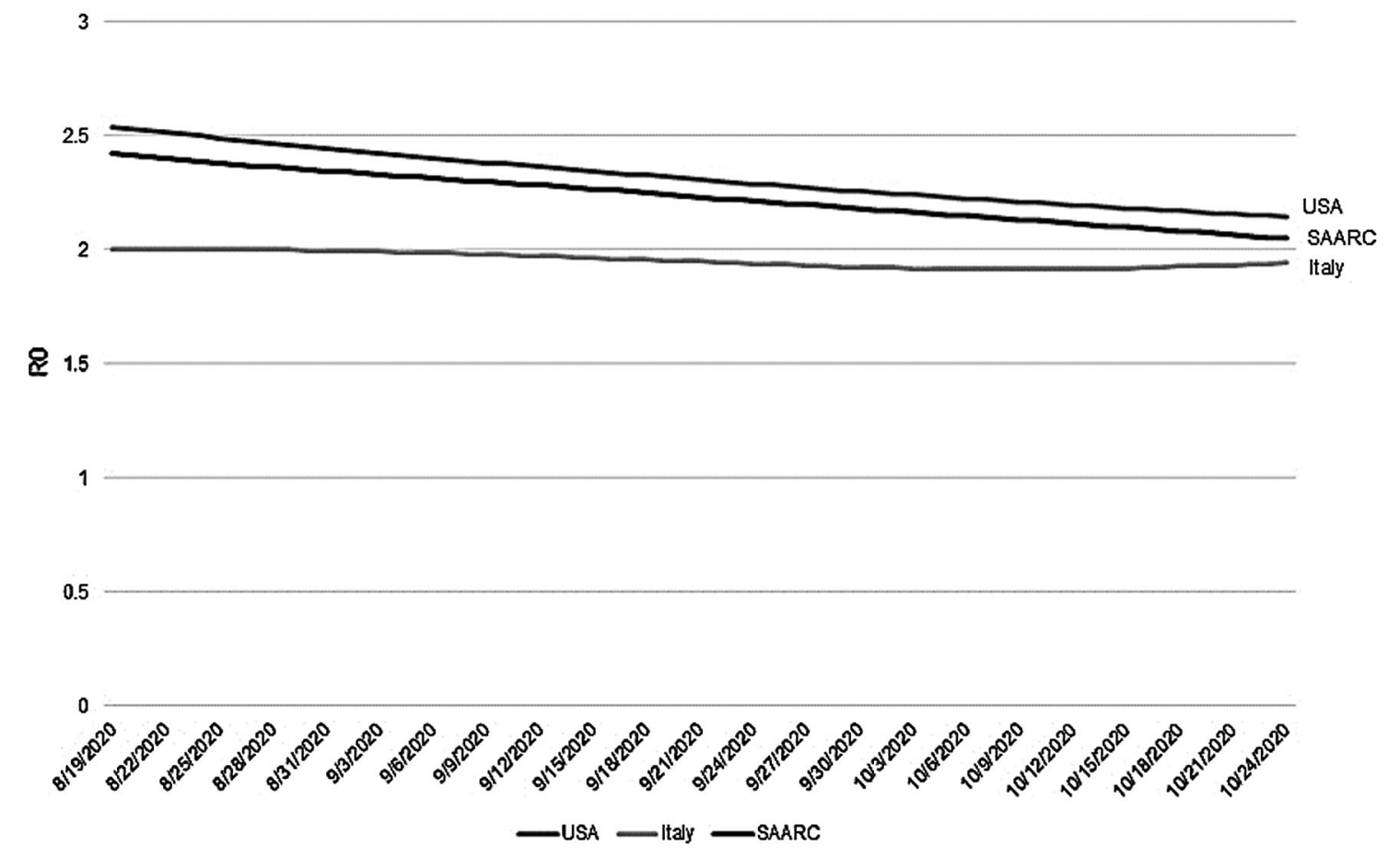

Figure 1: Comparison of $R_{0}$ of the SAARC region with the USA and Italy

\subsubsection{Social Distancing}

Maintaining a reasonable social distance and avoiding crowded areas is the most effective technique for controlling the transmission of COVID-19. To limit virus transmission while performing business operations, social distancing must be imposed to prevent close contact. It is challenging to implement without educating and training people. Social distancing is a good technique for controlling an epidemic situation without affecting the economy of the country. It would be practical to isolate patients and separate suspects in quarantine centers to obtain more desirable social distancing results. The most important thing is to control the epidemic by minimizing the contact ratio $(\alpha)$ of infected patients with others, which must be ensured with the proper isolation of patients in the isolation ward with proper SOPs. Precautionary measures are also implemented in hospitals, such as surgical face masks, safety kits, and hand sanitizer.

\subsubsection{Lockdown}

Lockdown is another strategy for controlling the epidemic quickly, as the Wuhan lockdown efficiently controlled the virus spread to other parts of China. However, intensive screening and social distancing are required to further restrict the local spread of the virus [14]. A strict, preplanned country-wide one-month lockdown in France showed an $83 \%$ reduction in predicated deaths, when more than one quarter of the French population was infected by COVID-19 before 19 March 2020 [15]. One study analyzed the effect of lockdown in various Indian states and recommended lockdown if the mortality rate was higher there [16]. The ill effects of lockdown on the economy outweigh its benefits if it is not properly planned [17]. Therefore, the success of a lockdown strategy largely depends on the activities planned to control the spread of the virus and the damage due to the spread of the virus; otherwise, it affects a country's economy. A lockdown aims not to contain the disease, but rather to train people to learn the scientific strategies for treating patients with COVID-19; if this is not achieved, the lockdown can no longer help [18].

The healthcare systems of these countries are already unable to serve the large populations and are not efficient enough to provide on-the-spot health facilities. Infectious diseases, such as TB, cholera, hepatitis, 
and many others, are almost diminished in developing countries due to hygienic and standard medical services but are common in SAARC countries. Lockdown would also assist the SAARC nations in developing healthcare services and successfully delaying the peak period of infection.

\subsection{Controlling COVID-19 in the SAARC Countries}

These tactics, especially lockdowns, have been applied to a varying degree in the SAARC countries, depending on the decisions of their governments. These tactics are also intended to teach the public to navigate the COVID-19 crisis. Compared with the USA and Italy, SAARC countries have fewer financial resources and have done fewer experiments, but they focus primarily on lockdown tactics that make their financial conditions much worse.

\subsubsection{Social Distancing}

Pakistan, India, and Bangladesh are among the ten most populous countries in the world. Due to their large populations and poor economic conditions, their lifestyle is entirely different from other developed countries. Most people live in the same household as several other family members and commonly share resources without restriction. The living habits are also unhygienic, such as taking food without hand washing, drinking polluted water, and having close social contact. The working conditions in factories and offices are also not healthy, and workers must work in close contact with each other due to the limited working space and manual labor. So, it is difficult to apply social distancing in these countries.

Restricting mass movements would be an efficient means of regulating COVID-19 in China, but it is not easy to enforce due to the large population and family size. Restrictions may include limiting social events, banning public movement, wearing a face mask, and accepting work from home to produce positive results [18]. The death rate in the United States is significantly influenced by social isolation, but numerous social standards impede these calculations [19]. Due to a shortage of infrastructure, it is challenging to establish adequate isolation wards in hospitals in SAARC countries. India and Pakistan have already reported several cases of mismanagement during patient care in hospitals and quarantine. When treating COVID-19 patients, doctors, and paramedical personnel themselves are not fitted with appropriate protection kits. Hospitals must be supported with proper quarantine centers to retain suspected patients and patients with initial symptoms for the incubation period to minimize the transmission rate. Due to mismanagement in quarantine facilities in the SAARC countries, as reported at the Taftan border in Pakistan during the initial outbreak of COVID-19, the chance of virus spread is much higher [20].

\subsubsection{Lockdown}

In the SAARC countries, due to different factors such as the slow economic growth rate, low average monthly wages, high inflation rate, and diversified cultural and social life patterns, the implementation of lockdown is not feasible. Pakistan is significantly affected by COVID-19 [21], and the lockdown could magnify the situation. The governments of these countries have limited resources, so they cannot provide proper relief packages for an extended period. Any relief package distribution would lead towards an increased risk of virus spread due to the large population that would not be managed properly.

The SAARC countries imposed an early lockdown to control COVID-19; otherwise, the situation would not be under control. The initial $R_{0}$ in the early stage of the outbreak in the SAARC region was much higher and represented a rapid increase in virus spread. Due to the lockdown, a decreasing trend in $R_{0}$ was also observed, as shown in Fig. 1. The lockdown must be continued to obtain a value of $R_{0}<1$, but it adversely affects the economy and living conditions of poor and middle-class families. Therefore, it would be better to continue smart lockdown with social distancing and strict SOPs to continue business operations. The government of Pakistan has already announced a smart lockdown to block only those areas where positive cases of COVID-19 have been identified and has developed SOPs for operating various businesses [22]. 


\subsubsection{Smart Lockdown Scheme}

Smart lockdown simply blocks a part of the city having positive COVID-19 cases, whereas other adjoining areas without COVID-19 cases do not have lockdown. It would not be effective in reducing the value of $R_{0}$, as restricting all movement in the infected part of the city would not be possible due to the layout of populous cities in the SAARC countries. Due to low monthly revenue, a complete, indefinite lockdown would not be productive for a long time. In such a scenario, individuals try to breach lockdowns to earn their livelihood, making the situation more complicated. Any technique to improve the value of $R_{0}$ will largely depend on educating the public about social distancing and business SOPs. In the case of COVID-19, the decline in number of infected persons depends only on the strong human immune system, the transmission rate is not controllable but can be lowered by using precautionary measurements. Due to the local social-cultural lifestyle of the SAARC nations, the implementation of these techniques is not easy, so some strict mechanisms in the form of a smart lockdown are needed. The SAARC countries lifted almost all forms of lockdown and social distancing in government offices, schools, universities, and public gathering areas at the end of September 2020, but it was not a wise decision, as suggested in the strategy proposed in this paper.

\section{Methodology}

\subsection{Proposed Multi-Stage Intelligent Smart Lockdown}

A modified scheme of smart lockdown, a multi-stage intelligent smart lockdown strategy, is proposed in this paper, which is entirely different from smart lockdown. There is no option to implement lockdown indefinitely, as it would be detrimental to the economy. In the same way, lifting lockdown would result in a rapid increase in the virus. The impact of a lockdown or its lifting cannot be observed if the duration of lockdown or lifting is less than the incubation period. For this purpose, various lockdown strategies are implemented dynamically in different stages, which are automatically adjusted based on the data of the last ten days. A simple SIR model cannot be implemented due to social distancing and precautionary measurements, which may minimize the spread of the virus. A continuous no-lockdown will increase the contact ratio, which increases the rate of virus spread.

Thus, we propose the dynamic SIR model based on an $R_{0}$ updated every ten days, as shown in Fig. 2. The $R_{0}$ value is critical to determining epidemic growth if other parameters are assumed to be constant. Four stages are defined for implementing various levels of lockdown, as shown in Tab. 1. A full lockdown approach will be implemented in the case of a high value of $R_{0}$ and exponential growth of the disease. If the value of $R_{0}$ is below 3.5, the country will enter stage-2 and implement lockdown for twenty days followed by ten days of business activities with specific SOPs, maintaining social distancing, and adopting precautionary measures.

Just after starting the business activities for the first ten days, complete lockdown is again applied for the remaining days of the month, as more than a one-month lockdown is not feasible in the SAARC countries. There is no benefit of lockdown if strict policies and SOPs do not follow the proposed strategy. This practice continues until the overall value of $R_{0}$ declines to 2.5 , and the country enters stage-3 lockdown. Now twenty days of business activities are followed by ten days of lockdown. As the value of $R_{0}$ further improves to 1.5 , the country enters stage- 4 when no lockdown is needed, but strict SOPs must be followed. If the value of $R_{0}$ decreases to 1.0 or less, then some of the business SOPs may be revised while a minimum level of SOPs and social distancing are maintained until the COVID-19 vaccine is available.

The data are used to implement the SIR model to identify the average $R_{0}$, contact ratios, and mortality rate using the data from the last 30 days for different countries, which is further used to implement the proposed strategy. In implementing the proposed strategy, $R_{0}$ is adjusted every ten days using the rate of change in $R_{0}$ to decide on the lockdown stage. 


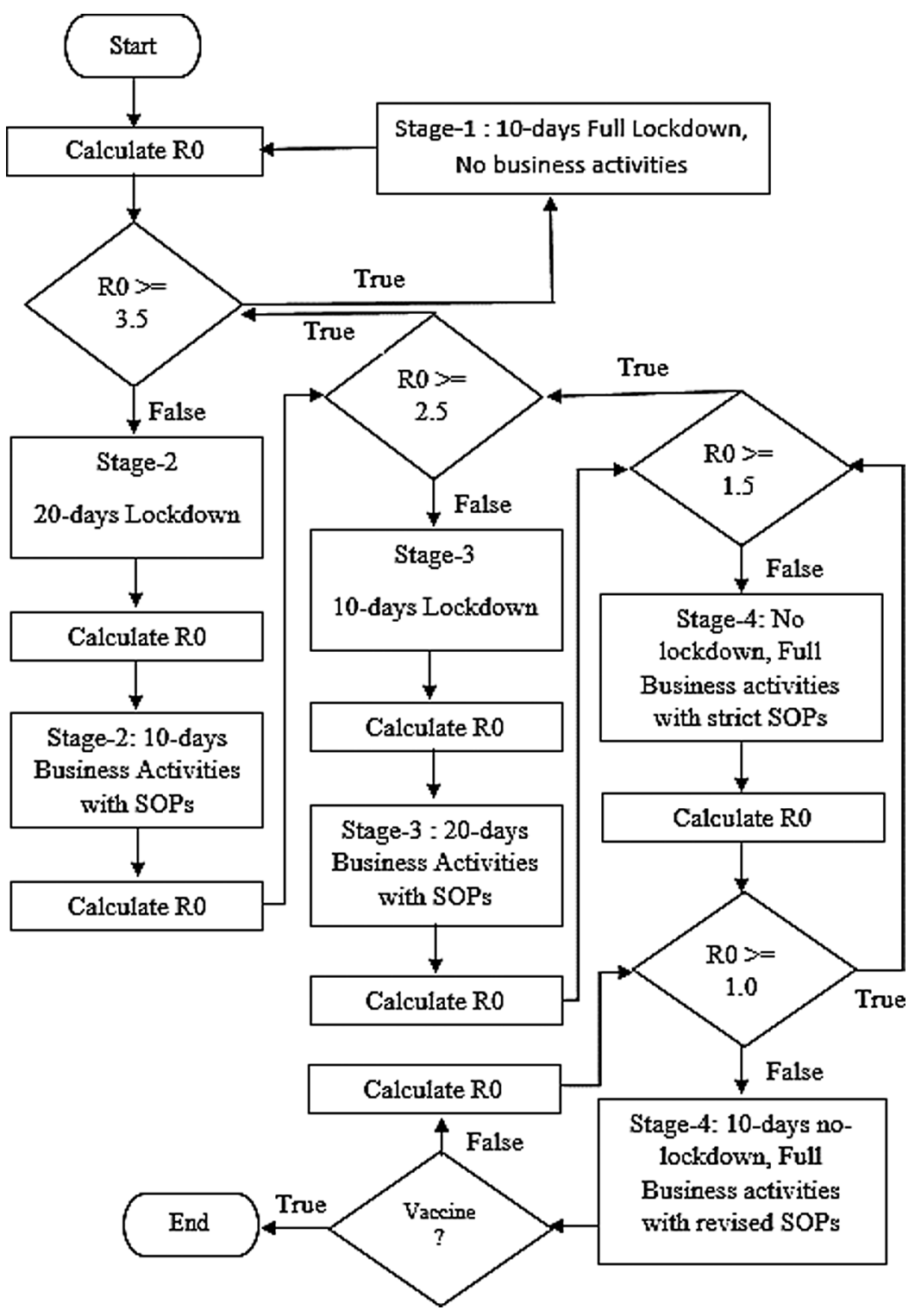

Figure 2: Intelligent smart lockdown strategy working model

Table 1: Intelligent smart lockdown stages

\begin{tabular}{llll}
\hline Stage & $\mathrm{R}_{0}$ & Lockdown Period & Business Activity Period \\
\hline 1 & $>=3.5$ & 30 & 0 \\
2 & $>=2.5$ and $<3.5$ & 20 & 10 \\
3 & $>=1.5$ and $<2.5$ & 10 & 20 \\
4 & $<1.5$ & 0 & 30 \\
\hline
\end{tabular}




\subsection{Parameters used in the Proposed System}

The average value of $R_{0}$, which is recalculated every 10 days using data for the infected, recovered, and susceptible population, is the main parameter used in the proposed system to determine the country's lockdown strategy, as shown in Tab. 1 . The rate of change in $R_{0}$ is also an important parameter to determine the current lockdown stage dynamically to manage the COVID-19 pandemic.

\subsection{Data Source}

The reported cases of COVID-19 in the SAARC countries were collected from the COVID-19 information portal from February 15, 2020 to October 24, 2020 [23]. As shown in Tab. 2, the sample data includes cumulative infectious cases, cumulative active infectious cases, cumulative recovered, and cumulative deaths each day for each of the SAARC countries. It is impossible to show the complete data here, but some data are represented and the dots in Tab. 2 show the continuity of the dataset up to the most recent 30 days.

Table 2: Actual COVID-19 data and parameters of the SIR model in the SAARC countries

\begin{tabular}{|c|c|c|c|c|c|c|c|c|c|c|c|c|}
\hline Sr. No & Date & $\begin{array}{l}\text { Day } \\
(\mathrm{t})\end{array}$ & $\begin{array}{l}\text { Total } \\
\text { Cases }\end{array}$ & $\begin{array}{l}\text { Active } \\
\text { Cases }\end{array}$ & $\begin{array}{l}\text { Recovered }+ \\
\text { Deaths }\end{array}$ & $\mu$ & $\beta$ & $\mathrm{R}_{0}$ & $\Delta \mathrm{R}_{0}$ & $\gamma$ & $\alpha$ & $\vartheta$ \\
\hline \multicolumn{13}{|c|}{ Pakistan } \\
\hline 1 & $9 / 25 / 2020$ & 213 & 309015 & 7831 & 307628 & 0.051 & 0.093 & 1.821 & 5.454 & 0.02 & 4.669 & 2.144 \\
\hline 2 & $9 / 26 / 2020$ & 214 & 309581 & 7797 & 308235 & 0.051 & 0.093 & 1.817 & 5.502 & 0.02 & 4.658 & 2.136 \\
\hline \multicolumn{13}{|l|}{.. } \\
\hline 29 & $10 / 23 / 2020$ & 241 & 326216 & 9855 & 323076 & 0.051 & 0.090 & 1.744 & 3.206 & 0.02 & 4.472 & 1.890 \\
\hline 30 & $10 / 24 / 2020$ & 242 & 327063 & 10235 & 323555 & 0.051 & 0.090 & 1.744 & 3.272 & 0.02 & 4.472 & 1.889 \\
\hline \multicolumn{13}{|c|}{ Sri Lanka } \\
\hline 1 & $9 / 25 / 2020$ & 224 & 3345 & 164 & 3184 & 0.051 & 0.074 & 1.449 & 8.314 & 0.02 & 3.716 & 0.917 \\
\hline 2 & $9 / 26 / 2020$ & 225 & 3349 & 150 & 3212 & 0.051 & 0.074 & 1.434 & 8.295 & 0.02 & 3.678 & 0.907 \\
\hline \multicolumn{13}{|l|}{.. } \\
\hline 29 & $10 / 23 / 2020$ & 252 & 7153 & 3495 & 3672 & 0.051 & 0.080 & 1.631 & 7.394 & 0.02 & 4.183 & 0.582 \\
\hline 30 & $10 / 24 / 2020$ & 253 & 7521 & 3792 & 3744 & 0.051 & 0.080 & 1.635 & 7.675 & 0.02 & 4.193 & 0.577 \\
\hline
\end{tabular}

\subsection{The SIR Model Dynamic Implementation}

The SIR model is a simple but important mathematical model for understanding the impact of the epidemic. It divides the overall population $N$ into three groups: susceptible, infectious, and recovered. As there is no vaccine or medicine available to cure the coronavirus, all the population is considered susceptible, $S$, and can get the disease through interaction with other infectious persons. Every person who tests positive for the coronavirus is in an infectious group called $I$. With special care in quarantine and support facilities in hospitals, a patient may recover. Due to the non-availability of medical equipment, or a severe coronavirus attack, a patient may die. In both cases, the case will be added to the third group, $R$.

$s(t+\Delta t)-s(t)=-\beta(t) \frac{s(t)}{N} \Delta t$ 
$i(t+\Delta t)-i(t)=-\beta i(t) \frac{s(t)}{S} \Delta t-\mu i(t) \Delta t$

$r(t+\Delta t)-r(t)=\mu i(t) \Delta t$

$s(t)$ is the proportion of those who are susceptible in the total population. As all have an equal chance of getting the disease, $N=s(t)$. By changing Eqs. (2) and (3):

$s(t+\Delta t)-s(t)=-\beta i(t) \Delta t$

$i(t+\Delta t)-i(t)=\beta i(t) \Delta t-\mu i(t) \Delta t$

On day $t$, the model represents $i(t)$ cumulative infectious patients, $r(t)$ recovered or deaths, and $s(t)$ noninfected population. $\beta$ is the effective daily infection rate, further divided into transmission rate $(\gamma)$ and contact ratio $(\alpha)$. If an infectious person has several contacts in a day, then the chance of transmission is greater, and the value of $\beta$ is increased. The value of $\mu$, the recoverability rate, is the number of days needed for a patient to recover. In the case of coronavirus, the patient will recover after 7-14 days. In the case of elderly patients with severe conditions, it takes more time. A high mortality rate of $22.8 \%$ is reported in patients above 70 years old [24]. In this paper, a dynamic SIR model is implemented by recalculating the contact ratio and $R_{0}$ every ten days and assuming all other parameters remain constant. After finding the new contact ratio and $R_{0}$ value, the SIR model is implemented to forecast the epidemic threat.

\subsubsection{SIR Model Assumptions and Initial Settings}

The SIR model is implemented with some assumptions. There is no change in the facilities already available, as it could be challenging to add new medical facilities during the epidemic. A recovered person will not be infected again because they have developed immunity against the virus. The transmission rate is uncontrollable and can only be lowered if an infected person has fewer contacts. Every person can be infectious if they contact other infected persons. It is only the immune system that helps one recover, as no vaccine is available, although isolation wards, quarantine centers, and other facilities provide recovery support. Thus, the value of $\mu$ remains constant for the duration of an epidemic. The contact ratio is the only way to reduce the impact of the epidemic. A low contact ratio through a properly managed lockdown and social distancing can delay the impact of the epidemic.

To implement the initial model, it is assumed that $i(0)=1, r(0)=0$, and $s(0)=S$. As there is no vaccine, $S=N$, where $N$ is the total population, $N=S+I+R$. In the case of our dynamic SIR model implementation, the initial setting is adjusted with actual active cases $i(t)$, actual recovered patients $r(t)$, and actual deaths $d(t)$ on a particular day t, whereas $r(t)$ includes both current recoveries and deaths.

$i(t)=i_{t}$

$r(t)=r_{t}+d_{t}$

$s(t)=S-i(t)-r(t)$

\subsubsection{Reproduction Number $R_{0}$}

The $R_{0}$ is a standard number representing the severity of the epidemic - the number of new cases due to an infectious person's contacts with a healthy population in a day. Different diseases have different standard $R_{0}$ values, which indicate the level of spread of those diseases if an epidemic breaks out in an area, as shown in Tab. 3 [25]. In the SIR model, the high $R_{0}$ value means there is a high risk of virus spread, and a high $R_{0}$ results in a high death toll, whereas $R_{0}=1$ means there may be risk, but there is no outbreak of the virus. There will be no further epidemic in the area, and disease will soon dissipate if $R_{0}$ is less than zero. The $R_{0}$ values of some of the most dangerous diseases indicate that the novel coronavirus is not more 
dangerous than those diseases, as shown in Tab. 3, but it is more dangerous than any other disease due to the non-availability of vaccines. Recently in the SAARC countries, a higher value of $R_{0}$ for COVID-19 between 3.5 and 4.5 has been observed, which indicates a higher risk and many deaths in the coming days than already observed in the previous months.

Table 3: $R_{0}$ of some most infectious diseases

\begin{tabular}{ll}
\hline Disease & $R_{0}$ \\
\hline Measles & $12-18$ \\
Chickenpox* & $10-12$ \\
Diphtheria & $6-7$ \\
Mumps & $4-7$ \\
Polio & $5-7$ \\
Rubella & $6-7$ \\
Smallpox & $5-7$ \\
COVID-19 & $2-5.7[26]$ \\
\hline
\end{tabular}

The value of $R_{0}$ depends upon the transmission rate and contact ratio. The transmission rate is the probability of a healthy person getting an infection due to contact with an infected patient. It depends upon the person's immune system and vaccine. As there is no vaccine available, the transmission rate is usually fixed and cannot be changed during the span of the epidemic. The second component of $R_{0}$ is the contact ratio: the number of contacts between an infected person and other healthy persons in a day. It can be controlled by social distancing and restricting the movements of people. Due to a more extended incubation period and the ability of carriers to transmit the virus to other susceptible people, the risk of transmission of the virus is high, and it can be controlled with extensive scaled screening to identify the infection at an early stage and separating infected patients immediately in quarantine centers to reduce the contact ratio.

\subsubsection{Impact of $R_{0}$ on Virus Spread}

The $R_{0}$ largely depends upon the number of contacts between an infected person and others in a day, and the number of days needed for a patient to recover, which directly affects the value of $R_{0}$. Due to the lifestyle in the SAARC countries, $R_{0}$ value can be expected to be very high. It was 4.92 on March 29, 2020 after seven days of outbreak in Pakistan, which indicates a high risk of virus spread, as can be observed over the following days. To reduce the $R_{0}$ value, governments must take serious steps. Only the contact ratio can be controlled by following specific SOPs and precautions, whereas the transmission rate is not controllable.

In the same way, the number of days needed for a patient to recover remains fixed due to the nonavailability of new healthcare systems during that period. In SAARC countries, the average recovery time was 19.5 days based on the initial data from COVID-19 patients. By implementing quarantine centers, it was observed that the value of $R_{0}$ had decreased to 1.74 in Pakistan by October 24, 2020. A consistent but prolonged increase of $5.6 \%$ in infection was observed during the initial phase on April 6, 2020, due to the population not following lockdown seriously. As a result, to control this infection, we observed a reduction of almost $74 \%$ in contact ratio on May 16, 2020 compared with the highest contact ratio on March 19, 2020 in Pakistan. 


\subsubsection{Impact of Lockdown on Contact Ratio ( $\alpha)$}

As in the implemented dynamic SIR model, when the $R_{0}$ is highest on March 19, 2020, the contact ratio is 14.31 in Pakistan, which is dangerously high. A high contact ratio is only controlled by an effective lockdown strategy with strict SOPs. The proposed smart, intelligent lockdown strategy will be implemented to control the rising value of the contact ratio and prevent an economic shutdown by following certain SOPs and social distancing. If strict SOPs are not implemented during the smart lockdown, then the infection will increase more rapidly, and the benefits of lockdown will vanish within a few days.

\subsubsection{Find Value of $\alpha$ and $R_{0}$}

The values of $\beta$ and other SIR model parameters are calculated by using the actual data from February 15, 2020 to June 15, 2020, as shown in Tab. 2. The active infectious cases can be calculated first by subtracting the recovered patients discharged from hospitals and the number of deaths on that day. From Eq. (5), we obtain Eqs. (10) and (11) through simplification.

$$
\begin{aligned}
& \frac{d i}{d t}=\beta i(t)-\mu i(t) \\
& \frac{d i}{d t}=(\beta-\mu) i(t)
\end{aligned}
$$

By integrating the above Eq. 11, we obtain Eq. 13.

$$
\begin{aligned}
& \int_{t=1}^{t=\infty} \frac{d i}{d t}=\int_{t=1}^{t=\infty}(\beta-\mu) i(t) \\
& i(t)=e^{(\beta-\mu) t} \times C
\end{aligned}
$$

As $i(0)=1, C$ is 1 , and it is reduced to Eq. 14 .

$\beta=\frac{\ln (i(t)-\mu t)}{t}$

By taking the logarithm of Eq. 14, we simplify it to obtain $\beta$.

$\beta=\frac{\ln (i(t)-\mu t)}{t}$

To calculate contact ratio, we assume $\gamma=2 \%$, whereas $\beta=\alpha \times \gamma \cdot \alpha$ is calculated as:

$R_{0}=\frac{\beta}{\mu}$

The values of $\beta$ and $\mu$ are used to calculate $R_{0}$ using Eq. 17 .

$R_{0}=\frac{\beta}{\mu}$

After applying the SIR model on the actual dataset, the average parameters for all the SAARC countries on October 24, 2020 were found and are shown in Tab. 4.

The average $R_{0}$ value is much higher than the current $R_{0}$ value in America and Italy, the countries most affected by COVID-19. India's $R_{0}$ value of 2.12 is the highest in the region; due to the high contact ratio there and because it has the largest economy of the SAARC countries. The average figures of the SAARC region are also critical. The value of $R_{0}$ is much improved in Pakistan, but it is still in stage-3 lockdown, where 
lifting the entire lockdown is not yet feasible. The mortality rate of $3.71 \%$ in Afghanistan is the highest of the SAARC countries. In the Maldives, the current value of $R_{0}$ indicates the COVID-19 situation is somewhat under control, and in the near-future there would be no need of any further lockdown. In Sri Lanka, the current situation is better than the previous, but due to the rise in the $R_{0}$ value, the second wave of COVID-19 is in the initial phase, and it can be controlled by implementing the proposed strategy. Similarly, the contact ratio in Nepal, Bangladesh, and Afghanistan is also much higher indicating an impeding second wave of COVID-19.

Table 4: Current SIR model parameters and ISL stage of the SAARC countries on October 24, 2020

\begin{tabular}{lllllll}
\hline Country & $\operatorname{Max} R_{0}$ & $R_{0}$ & $\Delta R_{0}(\%)$ & $\alpha$ & $\vartheta$ & ISL Stage \\
\hline Pakistan & 6.16 & 1.789 & 1.257 & 4.564 & 2.066 & Stage-3 \\
India & 4.34 & 2.118 & 2.379 & 5.421 & 1.534 & Stage-3 \\
Bangladesh & 6.15 & 2.029 & 2.318 & 5.203 & 1.452 & Stage-3 \\
Sri Lanka & 3.37 & 1.536 & -2.987 & 3.938 & 0.299 & Stage-3 \\
Nepal & 4.38 & 1.995 & 0.983 & 5.115 & 0.596 & Stage-3 \\
Maldives & 6.61 & 1.629 & 2.208 & 4.177 & 0.325 & Stage-3 \\
Bhutan & 2.13 & 1.324 & 2.996 & 3.395 & 0.000 & Stage-4 \\
Afghanistan & 3.79 & 1.726 & 1.650 & 4.427 & 3.710 & Stage-3 \\
Total & 4.77 & 2.129 & 2.317 & 5.460 & 1.547 & Stage-3 \\
\hline
\end{tabular}

Bhutan is the luckiest country with no deaths and in stage-4 lockdown in South Asia, where the current value of $R_{0}$ is 1.32, and never exceeds 2.13. The overall situation of the SAARC region is not out of danger, as the contact ratio is still greater than 5 , which indicates the implementation of some lockdown strategy instead of lifting all types of lockdowns.

The current lockdown stages of the intelligent smart lockdown strategy with the SIR model are derived from the current $R_{0}$ values of the SAARC countries, as shown in Tab. 4. Only Bhutan is in stage-4 due to their effective strategies for dealing with COVID-19, whereas all other SAARC countries are in stage-3 lockdown, and they are permitted to conduct business for twenty days in a month following a ten-day lockdown. There is no need for complete lockdown in any of the SAARC countries.

The proposed intelligent smart lockdown strategy is implemented with the dynamic SIR model and compared with other strategies, such as the no-lockdown strategy with the dynamic SIR model, and the full-lockdown with the dynamic SIR model. It is also compared with the simple SIR model as implemented in [6-8] to predict the infected, active infected, and recovered cases along with deaths in the SAARC countries.

\section{Results and Discussion}

The predicted results of the proposed multi-stage intelligent smart lockdown strategy with other techniques for controlling COVID-19 are shown in Fig. 3. The full lockdown approach shows the flattened curve of the infected population, but it will have destroyed the economy in the end. This shows that our proposed strategy is an effective method for delaying the peak period with fewer infected people compared with the simple SIR model and the no-lockdown approach, which is currently being followed by all SAARC countries. Without the subsequent lockdown, the sharp curve of the infected population indicates another wave of COVID-19 and an uncontrollable situation in the region. This can also be 
observed in all SAARC countries, and our proposed strategy shows a flattening curve compared with the nolockdown and simple SIR model. It shows an infected population of less than $1 \%$ except in India, as all the SAARC countries are currently in stage- 3 or stage-4 lockdown, along with performing business activities. In Pakistan's case, we see only $0.012 \%$ of the population, as shown in Tab. 5 , is affected by the proposed strategy, whereas $37.31 \%$ population will be affected without lockdown on April 24, 2021. It also shows a delay in the peak period, which would be May 3, 2021 in the case of the proposed strategy, whereas without any lockdown, it would be April 24, 2021 with the dynamic SIR model and September 19, 2021 with the simple SIR model.

It also shows that the positions of all the SAARC countries except India and Nepal would be better with the proposed strategy, and that the infected population would be less than $1 \%$ only, as shown in Tab. 5 . Destruction due to COVID-19 is at a peak in India in the SAARC region, where $4.36 \%$ would be affected by the proposed strategy by July 19, 2021, and nearly 38\% would be affected without a lockdown, as shown in Tab. 5.

Pakistan, India, and Bangladesh are the most affected countries in the SAARC region due to their large population and the mismanagement in controlling COVID-19. India has the highest number of infections due to COVID-19, as shown in Tab. 5. Simultaneously, there would be no severe problems in Sri Lanka and Bhutan due to their strategy to control COVID-19. Less than one thousand persons are infected due to COVID-19 in Bhutan with no deaths reported. The overall situation of the SAARC countries is satisfactory in stage-3 lockdown. However, a rising trend in $R_{0}$ is observed for most of the SAARC countries, which is a clear indication of a second wave in the region, so without implementing a proper lockdown strategy, they will not be able to control a new wave of COVID-19. Without a lockdown strategy, nearly $38 \%$ of the SAARC population will be affected, as shown in Fig. 4. They must implement an intelligent smart lockdown strategy to avoid the negative impact of the coming wave of COVID-19 while simultaneously mitigating the negative impact on their economies.

It will delay the peak infection period and reduce the infected population to nearly $4 \%$, as shown in Fig. 4. In this way these three SAARC countries Pakistan, India and Bangladesh can also manage resources to provide better healthcare services to patients and to minimize the mortality rate.

COVID-19 is a new virus with no remedy or vaccine. Moreover, the current healthcare systems of all the SAARC countries are insufficient to manage it. The healthcare systems of developed countries like Italy and the USA have also collapsed due to the high value of $R_{0}$ there. The SAARC countries, except Bhutan, are still hot spots of COVID-19 due to the rising trends in the value of $R_{0}$. The value of $R_{0}$ decreased from 7.43 to 2.13 after more than four months of various lockdowns from July, 2020 to October, 2020 in SAARC countries. Because of their financial problems, they must lift the lockdown due to continuous pressure from the public. Because of the slowdown in their economies, they cannot continue the lockdown. Over one-third of the SAARC population would be infected by March 3, 2021 without lockdown, and nearly $18 \%$ of the population would be infected by May 30, 2021 according to a simple SIR model. Due to the unique culture and social lifestyle of these countries, the contact ratio would rapidly increase without lockdown and would result in a higher value of $R_{0}$, and the SAARC countries will have become a danger for $1.56 \%$ of their infected population. The economic situation will be further worsened by the international economic crisis, which will lead to greater unemployment and poverty in the region. The ideal value of $R_{0}$ is less than one. It can be attained with a continuous lockdown of more than six months, which is not a feasible solution in the SAARC countries. Financial crises were observed in the region after two months of lockdown, with unemployment and slow economic growth. Thus, it is not a wise strategy for the SAARC countries, where per-capita income is much less than that of developed countries and $15.1 \%$ of the population was living below the poverty line in 2013 [27]. Therefore, a complete lockdown or curfew will adversely affect SAARC countries' economy and the lives of the poor. With the implementation of the multi-stage intelligent smart lockdown strategy, only $4.28 \%$ of the population will be infected after July 22, 2020 with no adverse impact on the economy. 
Pakistan

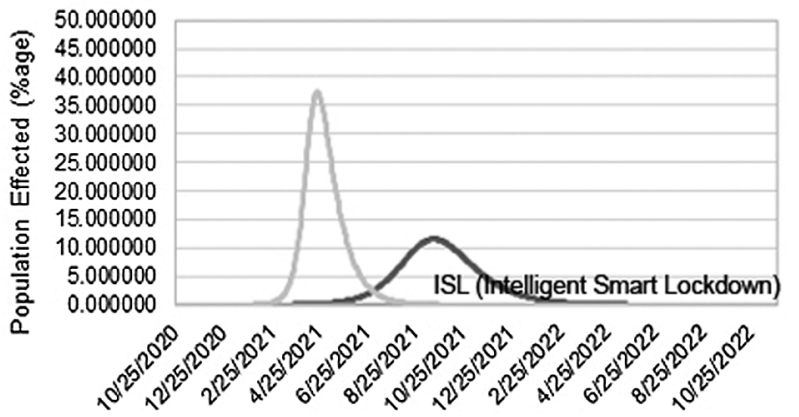

Bangladesh



Nepal



Bhutan

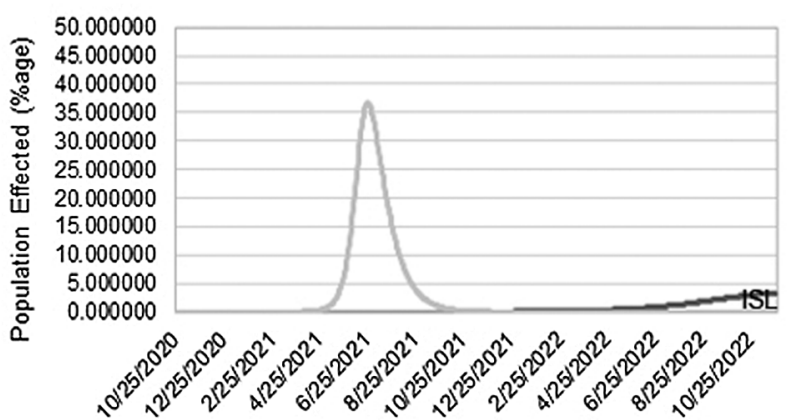

India

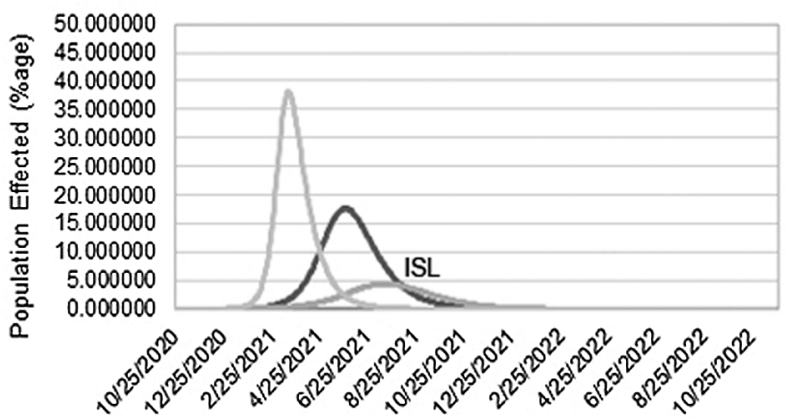

Sri Lanka



Maldives

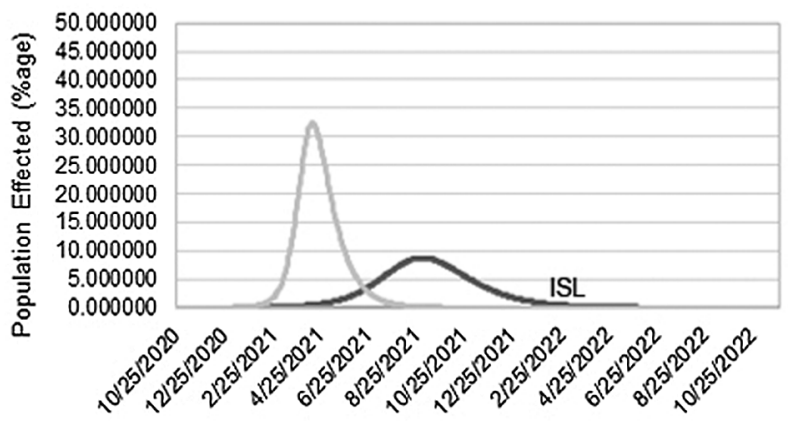

Afghanistan

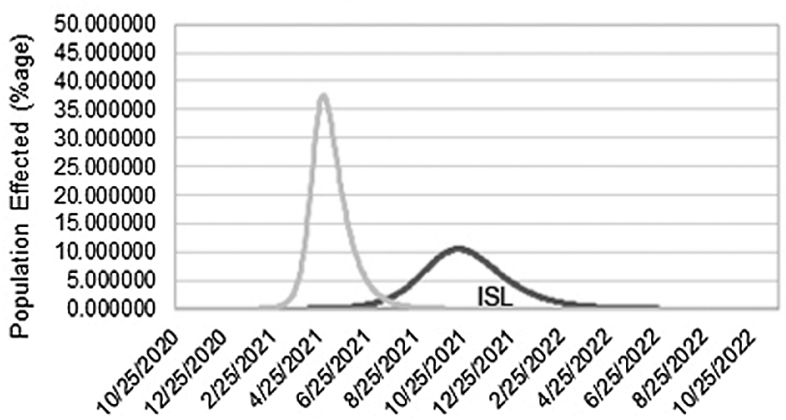

—SIR Model —Dynamic SIR Full Lockdown —Dynamic SIR Intelligent Smart Lockdown —Dynamic SIR No Lockdown

Figure 3: Comparison of intelligent smart lockdown in the SAARC countries with other strategies 
Table 5: Predicted results of COVID-19 using various strategies

\begin{tabular}{|c|c|c|c|c|c|c|c|c|c|c|c|c|}
\hline \multirow{2}{*}{$\begin{array}{l}\text { Strategy } \\
\text { Country }\end{array}$} & \multicolumn{3}{|c|}{$\begin{array}{l}\text { Intelligent smart lockdown } \\
\text { (Dynamic SIR model) }\end{array}$} & \multicolumn{3}{|c|}{ Simple SIR model } & \multicolumn{3}{|c|}{$\begin{array}{c}\text { No-lockdown } \\
\text { (Dynamic SIR model) }\end{array}$} & \multicolumn{3}{|c|}{$\begin{array}{c}\text { Full-lockdown } \\
\text { (Dynamic SIR model) }\end{array}$} \\
\hline & $\begin{array}{l}\text { Infected } \\
\text { population } \\
(\mathbf{0 0 0 )}\end{array}$ & $\%$ age & $\begin{array}{l}\text { Peak } \\
\text { date }\end{array}$ & $\begin{array}{l}\text { Infected } \\
\text { population } \\
(000)\end{array}$ & $\begin{array}{l}\% \\
\text { age }\end{array}$ & $\begin{array}{l}\text { Peak } \\
\text { date }\end{array}$ & $\begin{array}{l}\text { Infected } \\
\text { population } \\
(\mathbf{0 0 0 )}\end{array}$ & $\begin{array}{l}\% \\
\text { age }\end{array}$ & $\begin{array}{l}\text { Peak } \\
\text { date }\end{array}$ & $\begin{array}{l}\text { Infected } \\
\text { population } \\
(000)\end{array}$ & $\%$ age & $\begin{array}{l}\text { Peak } \\
\text { date }\end{array}$ \\
\hline Pakistan & 26010 & 0.012 & $\begin{array}{l}5 / 3 / \\
2021\end{array}$ & 25438298 & 11.54 & $\begin{array}{l}9 / 19 / \\
2021\end{array}$ & 82219453 & 37.31 & $\begin{array}{l}4 / 24 / \\
2021\end{array}$ & 3899 & 0.002 & $\begin{array}{l}3 / 4 / \\
2021\end{array}$ \\
\hline India & 60075070 & 4.358 & $\begin{array}{l}7 / 19 / \\
2021\end{array}$ & 242381627 & 17.58 & $\begin{array}{l}5 / 29 / \\
2021\end{array}$ & 524197739 & 38.03 & $\begin{array}{l}3 / 18 / \\
2021\end{array}$ & 623117 & 0.045 & $\begin{array}{l}2 / 11 / \\
2021\end{array}$ \\
\hline Bangladesh & 1381152 & 0.840 & $\begin{array}{l}7 / 22 / \\
2021\end{array}$ & 26388131 & 16.04 & $\begin{array}{l}7 / 1 / \\
2021\end{array}$ & 63310072 & 38.49 & $\begin{array}{l}5 / 30 / \\
2021\end{array}$ & 18632 & 0.011 & $\begin{array}{l}12 / 25 / \\
2020\end{array}$ \\
\hline Sri Lanka & 29 & 0.0001 & $\begin{array}{l}2 / 2 / \\
2021\end{array}$ & 1498926 & 7.00 & $\begin{array}{l}3 / 17 / \\
2022\end{array}$ & 8109294 & 37.89 & $\begin{array}{l}3 / 27 / \\
2021\end{array}$ & 29 & 0.0001 & $\begin{array}{l}12 / 13 / \\
2020\end{array}$ \\
\hline Nepal & 346982 & 1.194 & $\begin{array}{l}7 / 16 / \\
2021\end{array}$ & 4489182 & 15.44 & $\begin{array}{l}6 / 22 / \\
2021\end{array}$ & 10805427 & 37.17 & $\begin{array}{l}4 / 16 / \\
2021\end{array}$ & 5956 & 0.021 & $\begin{array}{l}2 / 11 / \\
2021\end{array}$ \\
\hline Maldives & 115 & 0.021 & $\begin{array}{l}3 / 4 / \\
2021\end{array}$ & 47103 & 8.73 & $\begin{array}{l}9 / 2 / \\
2021\end{array}$ & 174556 & 32.36 & $\begin{array}{l}6 / 27 / \\
2021\end{array}$ & 65 & 0.012 & $\begin{array}{l}1 / 12 / \\
2021\end{array}$ \\
\hline Bhutan & 1 & 0.0001 & $\begin{array}{l}1 / 3 / \\
2021\end{array}$ & 25348 & 3.29 & $\begin{array}{l}12 / 7 / \\
2022\end{array}$ & 282556 & 36.67 & $\begin{array}{l}3 / 4 / \\
2021\end{array}$ & 1 & 0.0001 & $\begin{array}{l}10 / 24 / \\
2020\end{array}$ \\
\hline Afghanistan & 2139 & 0.006 & $\begin{array}{l}3 / 3 / \\
2021\end{array}$ & 14555219 & 37.49 & $\begin{array}{l}12 / 21 / \\
2020\end{array}$ & 17788177 & 45.82 & $\begin{array}{l}3 / 8 / \\
2021\end{array}$ & 371 & 0.001 & $\begin{array}{l}2 / 1 / \\
2021\end{array}$ \\
\hline
\end{tabular}

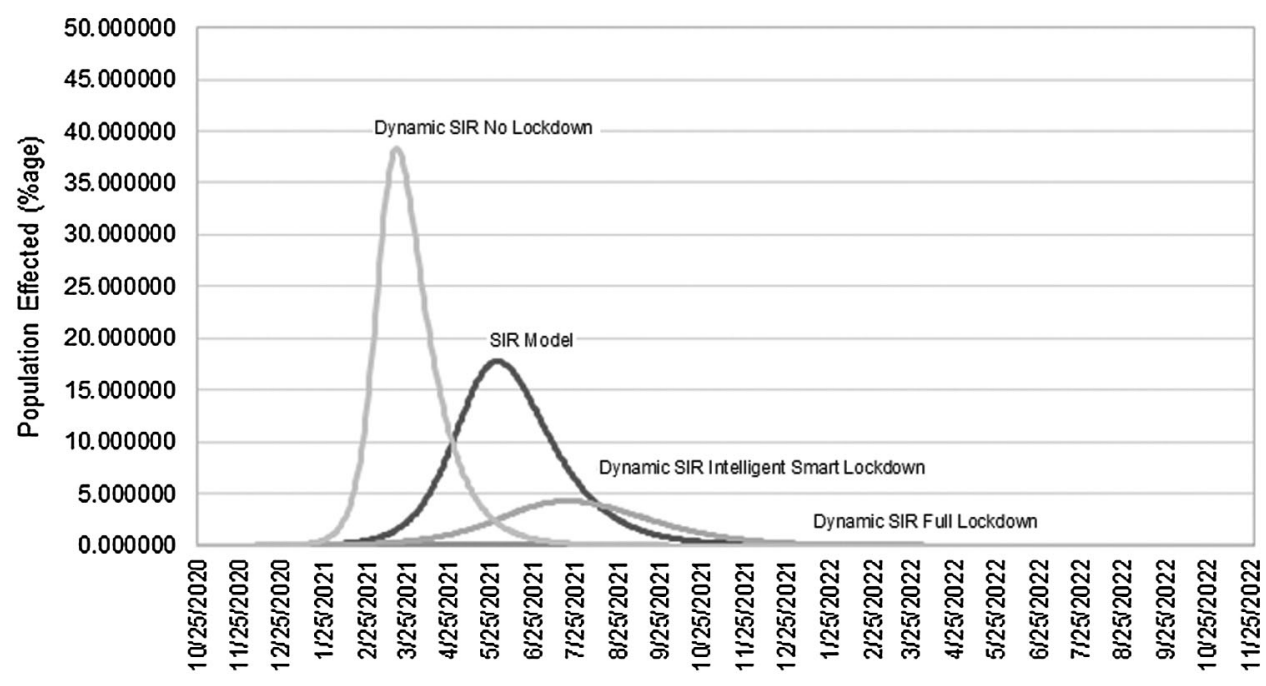

—SIR Model —Dynamic SIR Full Lockdown —Dynamic SIR Intelligent Smart Lockdown —Dynamic SIR No Lockdown

Figure 4: Overall impact of intelligent smart lockdown strategy in the SAARC region

\section{Limitation of Research}

The multi-stage intelligent smart lockdown strategy with a dynamic SIR model would be a practical solution compared with a simple SIR model. However, its implementation is the responsibility of the government, so actual evaluation of this technique is not possible until it is implemented in a metropolitan city and fully managed to observe the value of $R_{0}$ and to implement the lockdown stages dynamically to control the COVID-19 pandemic situation. 


\section{Conclusion}

Various SAARC governments have already implemented a smart lockdown after executing the full lockdown, which is not beneficial due to the virus's incubation period. An intelligent smart lockdown strategy is suggested in this paper: a multi-stage lockdown with social distancing and SOPs for doing business. It is implemented dynamically by calculating the $R_{0}$ value after a specified period. There are four lockdown stages to implement, based on the value of $R_{0}$. A high value of $R_{0}$ means a country must follow a stage- 1 lockdown without business operations. As the value of $R_{0}$ decreases due to the stage- 1 lockdown, the next stage of lockdown with economic activities for a certain period is implemented. There is no physical lockdown in the stage-4 lockdown, but strict SOPs must be followed until $R_{0}$ becomes less than one. Some of the SOPs offer flexibility, but a certain number of SOPs must be followed strictly until the vaccine is available. Implementing this strategy brought about a visible improvement in contact ratio and economic conditions. It is much better than a no-lockdown situation and does not affect the economy, as in the case of a full lockdown. This strategy also emphasizes social distancing, smart lockdowns, and specific SOPs for conducting businesses. It is useful for reducing psychological stress and fear about the financial crisis due to COVID-19. Due to the risk of a second wave of COVID-19, this strategy would be an effective solution for controlling it in less time. Thus, an intelligent smart lockdown strategy to manage COVID-19 would be an effective, desirable, and long-term solution for the SAARC and other countries of the world.

Acknowledgement: Thanks to our families \& colleagues, who supported us morally.

Funding statement: The authors received no specific funding for this study.

Conflicts of interest: The authors declare that they have no conflicts of interest to report regarding the present study.

\section{References}

[1] P. Zhou, X. L. Yang, X. G. Wang, B. Hu, L. Zhang et al., "A pneumonia outbreak associated with a new coronavirus of probable bat origin," Nature, vol. 579, no. 7798, pp. 270-273, 2020.

[2] CDC, "Situation summary," 2020. [Online]. Available at: https://www.cdc.gov/coronavirus/2019-nCoV/ summary.html.

[3] WHO, "Coronavirus disease 2019 situation," 2020. [Online]. Available at: https://www.who.int/docs/defaultsource/coronaviruse/situation-reports/20200402-sitrep-73-covid-19.pdf.

[4] The Lancet, "India under COVID-19 lockdown," Lancet, vol. 395, no. 10233, pp. 1315-1323, 2020.

[5] Our World in Data, “Total covid-19 tests per 1,000 people," 2020. [Online]. Available at: https://ourworldindata. org/grapher/full-list-cumulative-total-tests-per-thousand.

[6] N. R. Deyshappriya, "Examining poverty trends in South Asian countries: Where is Sri Lanka among its South Asian counterparts?," 2020. [Online]. Available at: https://blogs.lse.ac.uk/southasia/2018/07/31/examiningpoverty-trends-in-south-asian-countries-where-is-sri-lanka-among-its-south-asian-counterparts/.

[7] I. Nesteruk, "Statistics-based predictions of coronavirus epidemic spreading in mainland China," Innovative Biosystems and Bioengineering, vol. 4, no. 1, pp. 13-18, 2020.

[8] F. S. N. James, N. Dey and J. Chaki, Artificial intelligence for coronavirus outbreak. Germany: Springer Briefs in Applied Sciences and Technology, 2020.

[9] N. Masuda and P. Holme, "Predicting and controlling infectious disease epidemics using temporal networks," F1000 Prime Reports, vol. 5, pp. 6, 2013.

[10] H. Behncke, "Optimal control of deterministic epidemics," Optimal Control Applications and Methods, vol. 269, no. 6, pp. 269-285, 2001. 
[11] S. M. Kissler, C. Tedijanto, M. Lipsitch and Y. Grad, "Social distancing strategies for curbing the covid19 epidemic," Medrxiv, vol. 2020, pp. 1-21, 2020.

[12] T. P. Sonam Ongmo, "What explains Bhutan's success battling covid-19?," 2020. [Online]. Available at: https:// thediplomat.com/2020/05/what-explains-bhutans-success-battling-covid-19.

[13] Republica, "First case of coronavirus confirmed in Nepal," 2020. [Online]. Available at: https://myrepublica. nagariknetwork.com/news/85603/.

[14] T. Peng, X. L. H. Ni, Z. Cui and L. Du, "Wuhan city lockdown and nationwide intensive community screening are effective in controlling covid-19 epidemic: Analysis based on a modified sir model," Lancet, vol. 396, no. 10243, pp. 1-20, 2020.

[15] J. Roux, C. Massonnaud and P. Crepey, "Covid-19: One-month impact of the french lockdown on the epidemic," Medrxiv, vol. 2020, pp. 1-20, 2020.

[16] T. Sardar, S. S. Nadim and C. Joydev, "Assessment of 21 days lockdown effect in some states and overall India: a predictive mathematical study on COVID-19 outbreak," Arxiv Preprint Arxiv, vol. 2020, pp. 1-10, 2020.

[17] M. J. Umoh, I. R. Nseobot, Y. Hamid, S. Elyassami, A. I. Effiong et al., "Covid-19 city locked down: Implications on welfare in developing countries," International Journal of Business Education and Management Studies, vol. 5, no. 3, pp. 6-13, 2020.

[18] A. W. Smith and D. O. Freedman, "Isolation, quarantine, social distancing and community containment: Pivotal role for old-style public health measures in the novel coronavirus outbreak," Journal of Travel Medicine, vol. 27, no. 2, pp. 1-12, 2020.

[19] M. Greenstone and V. Nigam, "Does social distancing matter?," University of Chicago, USA: SSRN University of Chicago, Becker Friedman Institute for Economics, 2020.

[20] AFP, "Squalid taftan quarantine camps present a sorry state of affairs," 2020. [Online]. Available at: https://www. dawn.com/news/1542153.

[21] U. W. Chohan, "Forecasting the economic impact of coronavirus on developing countries: Case of Pakistan," CASS Working papers on Economics \& National Affairs, vol. 2020, pp. 1-26, 2020.

[22] A. Mahmood, "Ease in lockdown sets in confusion in Punjab," 2020. [Online]. Available at: https://www.dawn. com/news/1549562.

[23] Worldometers, "Coronovirus updates (live)," 2020. [Online]. Available at: https://www.worldometers.info/ coronavirus/.

[24] M. Ketchell, "Why are older people more at risk of coronavirus?," 2020. [Online]. Available at: https:// theconversation.com/why-are-older-people-more-at-risk-of-coronavirus-133770.

[25] WHO, "History and epidemiology of global smallpox eradication," Centers for Disease Control and Prevention, US, 2020. [Online]. Available at: https://stacks.cdc.gov/view/cdc/27929.

[26] S. Sanche, Y. T. Lin, C. Xu, E. R. Severson, N. Hengartner et al., "High contagiousness and rapid spread of severe acute respiratory syndrome coronavirus 2," Emerging Infectious Diseases, vol. 26, no. 7, pp. 1470-1477, 2020.

[27] N. R. Deyshappriya, "Examining poverty trends in South Asian countries: Where is Sri Lanka among its South Asian counterparts?," 2020. [Online]. Available at: https://blogs.lse.ac.uk/southasia/2018/07/31/examiningpoverty-trends-in-south-asian-countries-where-is-sri-lanka-among-its-south-asian-counterparts/. 